\title{
Affective Politics in Gendered Organizations: Affirmative Notes on Becoming-Woman
}

\author{
Alison Pullen, Macquarie University \\ Carl Rhodes, UTS Business School \\ Torkild Thanem, Stockholm, Business School
}

\begin{abstract}
Current approaches to the study of affective relations are over-determined in a way that ignores their radicality, yet abstracted to such an extent that the corporeality and differentially lived experience of power and resistance is neglected. To radicalize the potential of everyday affects, this paper calls for an intensification of corporeality in affect research. We do this by exploring the affective trajectory of 'becoming-woman' as introduced by. Deleuze and Guattari. Becoming-woman is a process of gendered deterritorialization and a specific variation on becoming-minoritarian. Rather than a reference to empirical women, becomingwoman is a necessary force of critique against the phallogocentric powers that shape and constrain working lives in gendered organizations. Whereas extant research on gendered organizations tends to focus on the overwhelming power of oppressive gender structures, engaging with becoming-woman releases affective flows and possibilities that contest and transgress the increasingly subtle and confusing ways in which the gendered organizations affect people at work. Through becoming-woman an affective and affirmative politics capable of resisting the effects of gendered organization becomes possible. This serves to further challenge gendered oppression in organizations, and to affirm a life beyond the harsh limits that gender can impose.
\end{abstract}

Keywords: Affect, affirmative politics, becoming-woman, corporeality, gendered organizations, ontology, power, resistance. 


\section{Prologue}

Since Acker (1990) famously coined the term 'the gendered organization', it has been productively considered in relation to significant problems such as sexual harassment (Rogers and Henson, 1997), sex in/equality (Acker, 2011), the gender pay-gap (Misra and MurayClose, 2014), gendered hierarchy (Murray and Syed, 2009), gendered power relations (Townsley, 2003), and male-dominated work cultures (Dellinger, 2002). The importance of these problems is undeniable, not the least in terms of how they impinge on individuals' everyday lives in organizations. The gendered organization operates beyond and beneath the level of ideas and debates, infiltrating everyday experience as we are moved by mundane gendered encounters that generate affective experiences in our bodies. Underpinned by inequity, such encounters are predicated on the sex of our bodies and the gendering of our performances.

By way of example, I (one of the authors) recall an incident when I found myself in an elevator with my boss. He blatantly ignored me. Eye contact was averted. He acted as if I was not there. I felt awkward. I knew he could see me, just as I could see him. I was silent. It was clear he wanted no interaction. My spine shrank as I wanted to melt away into the floor, and yet I forced my neck stiff to ensure that I did not appear intimidated. My body shook with subdued anger and my stomach churned. I simultaneously wanted to avoid him and to speak out in resistance. Remaining silent, my body pulsated uncontrollably. I looked to the floor for a moment, and my foot was tapping anxiously. I could feel my face get warmer, as the blood rushed through my veins. The corners of my eyes started to squint as I focused on waiting for the doors of the elevator to open.

This seemingly unremarkable experience raised many questions: Why would someone do this? Who could act like that? Is this guy an idiot? Or, maybe this behaviour is symptomatic of a bigger issue? These questions mattered, but more imposing was the way I felt. I was filled with a sense of awkwardness; out of place, embarrassed, angry, and shamed. These affects, every one negative, led to more questions. Who am I in this masculine and maledominated organization? Why do I allow this person to make me feel this way? How am I perceived to be, when I am treated in such a manner? The encounter lasted only a few moments, but it lived on in my body. I felt it on, through and under my skin.

A few weeks later I had to contact him about an important issue at work. I sent him an email. That was months ago, and I still haven't had a reply. He must have felt no need to acknowledge me or to respond in any way. Even so, the issues I wrote to him about were central to the nature of my work and to the future of my relationship with the organization. It was of great importance to me. An impulse to rationalize kicked in. Perhaps he is overworked or shy? Maybe I am of no value to him or the institution he represents? Ignored again, I felt angry, disappointed, vulnerable and humiliated. The power of these affects outweighed anything I could muster to rationalize the situation. These particular affects did not stand in isolation. They build on affects still sitting in my body from the encounter in the elevator.

Everyday experiences like the ones just described generate affective responses; responses that live on in our flesh, layered as new events unfold that remind the body how it feels to feel. These mundane events register in the shift of affects, and they repeat and spiral with intensity. Affects don't just go away, especially if being marginalized is a significant part of your organizational experience. On-going experiences of being othered meet the affection caused by everyday encounters, and they build momentum. In some cases they create a 
fleeting sense of who I am in the gendered organization. Affects live on through their subjective expressions. While these are small incidents, they are not isolated ones. They represent a bigger problem of exclusion, lack of transparency, and divisive culture. Furthermore these affects offer insights into gender at work, and to everyday relations that are painful yet deemed acceptable.

Now, what if our affective embodied responses to the gendered organization could be engaged with affirmatively, rather than in ways that diminish us? What if these affects could provide us with a political springboard for addressing and combating the often harsh realities of gendered organizations?

\section{Beginning}

En route towards developing an affective politics of gendered organizations, this paper sets out to examine how everyday affects are experienced in relation to gendered forms of oppression in work and organizations. Our paper also explores how such affects can trigger a radical politics, which challenges gendered oppression in organizations, and which affirms a life beyond the suffocating constraints that gender can impose. This is important because an affective politics alerts us to, and helps us resist and transgress, the increasingly subtle and confusing ways in which the gendered organization works its way into our lives, rather than being dumbfounded by rumours of its death or overwhelmed by exaggerated claims of its power.

We begin by unwrapping our understanding of the gendered organization, of affect and of affective politics in relation to previous writings in this area. We then explore how the trajectory of 'becoming-woman' may be mobilized for an affective politics in gendered organizations. In doing so, we take inspiration from Spinoza's idea of affectus which informed Deleuze and Guattari's philosophy and thinking on affect. We go on to discuss in detail the importance of Deleuze and Guattari's minoritarian politics through the affective process of becoming-woman. Deleuze and Guattari (1988) wrote about becoming-woman not as a simple reference to woman herself but as a process of deterritorialization and a specific variation on becoming-minoritarian. This is a process which contests ingrained subject positions and prevailing oppositions between self and other. Even though Deleuze and Guattari have been criticized for negating sexual difference, their work has been employed by feminists, notably Braidotti (1994, 2003) and Grosz (1994), who have shown what kind of possibilities their philosophy harbours. We draw attention to becoming-woman's importance as an affirmative critique of phallogocentric power in the context of gendered organizations. Becoming-woman releases affective flows and possibilities that transgress the complex and contradictory workings of the gendered organization in contemporary life and work. Through becoming-woman, an affective and affirmative politics capable of resisting the effects of gendered organization becomes possible.

The gendered organization emphasizes that gender is built into the very structure and culture of organizations, and acknowledges that individuals experience organizations through gendered advantage and disadvantage. Living and working in gendered organizations, we feel these experiences. They are practical and embodied. Yet, in recent years neo-liberal accounts have suggested that diversity management is transforming organizations into gender-neutral level playing fields (see e.g. Devillard et al, 2013; Wittenberg-Cox, 2014), while neo-Marxist ones have insinuated that gender is irrelevant now that capital expands itself across stratified 
identity groups in a quest for the total capitalization and exploitation of life (e.g. Smith, 2008; Fleming and Sturdy, 2009). We strongly disagree. Such claims are just as false today as when Acker (1990) first put forward her ground-breaking thesis. As long as male bodies and masculine values of bodily control and individualistic competitiveness are privileged in organizations, as long as men are paid more than women for performing the same job, as long as unequal family responsibilities undermine women's opportunities for equal participation (Ely et al., 2014), and as long as organizations demand a robot-like and gender-neutral worker who is free of sickness and domestic problems, who is ever obedient to the continuing demands of ensuring escalating productivity and effectiveness, gendered organizations will continue to shape and constrain lives.

Acker (1990) showed us how organizations enable and reinforce gendered oppression while simultaneously allowing it to be hidden. Rather than being gender-neutral, she made us realize that organizations are gender-blind - structurally and culturally masculine, yet infused with an ideal image of men's and women's bodies and bodily difference which is taken for granted, and which cloaks the unfair distribution of advantages and disadvantages between women and men. However, focusing on the overwhelming power of oppressive gender structures, research on gendered organizations (e.g. Gherardi, 1995; Fletcher, 1999; Britton, 2000; Stainback et al, 2015) tends to underestimate the contradictory and subtle ways in which the gendered organization often operates. As discriminatory practices are coupled with the encouragement to be our gender-free selves, women and men in organizations express and experience gender in a variety of hegemonic and non-hegemonic ways (Acker, 2006). While organizations intoxicated by the neo-liberal potion of diversity management (cf. Özbilgin and Tatli, 2011) are exploiting token women as evidence of gender equality and pretending that business performance is all that matters, they also encourage young aspiring women to 'work like a man', stay cool, and freeze their eggs (Time, 2014). There is a strong message that private lives, including motherhood and flexible working, is not part of the organization (Gatrell, 2013). To survive in such male-dominated work environments, many women at the beginning of their careers embrace the illusion of gender-neutrality, deny the existence of gender discrimination and turn a blind eye to sexual harassment (Lewis, 2014). For others, such experiences give rise to disillusionment, frustration, and a desire to create more just work environments. The gendered organization therefore demands continuous elaboration of how people can respond to the inequities that it breeds. Even though affect enables us to rethink how the oppression of gendered organization is felt, analysing the gendered organization also allows us to start thinking about how, through an affective politics, we can resist it and craft ways of living and working that transgress and subvert its limits.

With this paper we suggest that seemingly negative affects provide a fruitful departure point in our journey towards an affirmative affective politics. As we have noted above and as we have experienced in our working lives, negative affects may offer a platform for disrupting the status quo and create possibilities for change. One such example comes from previous writings on shame. Probyn (2004) has suggested that everyday shame harbours a positivity and constitutes a vehicle for "rethinking [...] how we conceptualise the everyday as it is lived" (p. 328). Embodied knowledge through which individuals feel and understand everyday organizational life is gained through shame and other negative affects. Such affects can make us question our ingrained assumptions about the organizations we inhabit. Like Gregg (2004), we think that radical political responses might intensify from local experiences of hegemonic structures, "creat[ing] affective connections between past, present and future political concerns" (p. 363). Given that the body is the site of such connections, it is through 
our bodies that we respond affectively and politically to the injustices of gendered organization. Instead of privatizing politics, shame is experienced by "differently positioned selves" in such a way that it is "contagious" (Probyn, 2004: 328). It turns into a collective affect that can join individuals with similar experiences into a common striving for change along a trajectory where shame and anguish give way not only to contempt and anger, but to surprise and joy, hope and thrill, that life in organizations may be different.

The affective politics that we are concerned with in this paper is underpinned by a relational ontology which dissolves the separation between culturally constructed emotions and the body's materiality, yet realizes the radical potential of mundane experiences in everyday organizational life. Appreciating that the body bridges everyday experience and political action, the gendered organization becomes a site of affective engagement, possibility and experience which works through and between individual bodies. Consequently, the gendered organization does not merely generate mundane negative affects, but becomes vulnerable to the radical politics that emerges from them. The gendered organization is both enabled and subverted by a complex interplay of affects where, for example, greed, disgust, suspicion, anxiety and shame are scrambled by pride, excitement, and confidence.

To consider affective politics, we locate our exposition within the affective turn in social and cultural theory as it has occurred in recent years. This turn to affect is greatly indebted to the writing of Deleuze and Guattari (see e.g. Massumi, 1995; 2002a; Clough, 2003; Ahmed, 2004; Braidotti, 2006; Gregg and Seighworth, 2010). First articulated by Deleuze and Guattari's (1988) translator Brian Massumi (1995), the affective turn is now well immersed in the social sciences and humanities, and has recently shown signs of making its way into certain corners of organization theory (see e.g. Kenny, 2012; Vachhani, 2013; Kenny and Fotaki, 2014; Thanem and Wallenberg, 2015). Although many of these contributions are torn between, and undermined by, abstract theorizing and a deterministic cultural politics, they enable us to appreciate that affects are pre-personal and extra-personal (Massumi, 1995; Shouse, 2005), an also social, political and corporeal (see e.g. Seyfert, 2012). Affects are not merely experienced viscerally, felt in isolation, processed mentally or expressed through bodily gestures. Instead, affects are infused with forces of desire and power to such an extent that they are shaped by and shape social processes. Passing between bodies with varying speed, duration and intensity, affects influence how we live, interact and work. Directed at selves and others, affects are invested in institutional and ideological constructs such as the gendered organization, as well as in the political ideas, acts and movements that challenge it.

Deleuze's engagement with affect, on his own and in his joint writings with Guattari (e.g. Deleuze, 1988, 1992, 1994; Deleuze and Guattari, 1984, 1988) resurrects hope that life can be different, no matter how forlorn things seem, and that such difference can be joyous. To some extent, this is already evident in organizational scholarship, which has drawn on Deleuze and Guattari's work to reimagine the heterogeneous couplings and indeterminate flows that underpin and change organizations (e.g. Tsoukas and Chia, 2002; Munro, 2004; Clegg, Kornberger and Rhodes, 2005; Linstead and Thanem, 2007), multiplying the variety of liveable lives (Thanem, 2004, 2006; Linstead and Pullen, 2006). But the political possibilities of affect, which Deleuze and Guattari began to articulate, remain largely neglected in this literature. Through their powerful analysis of capitalism, Deleuze and Guattari (1984) indicated that affects can subvert and exceed the suffocating technologies of capture, control, exploitation and oppression that underpin the capitalist order. And through their notion of becoming-woman (Deleuze and Guattari, 1988), they outlined an affective trajectory that rails against, and transgresses, the paradoxical ways in which life is exploited 
and oppressed by capital. Deleuze and Guattari spoke little of gender in organizations, but this makes it particularly intriguing to explore how becoming-woman may inform an affective politics against and beyond the gendered organization.

As we have indicated above, combatting the injustices of the gendered organization is as important as ever. To develop an affective politics which can be crafted against and beyond the gendered organization, our paper now unfolds in four main sections. In the next section, named 'Affecting', we establish our position within existing theoretical approaches to affect, as it has developed from Benedict de Spinoza's $17^{\text {th }}$ century philosophy. In tracing the development of the contemporary 'affective turn' in social and cultural theory we raise the possibilities of an embodied affective politics that avoids the twin risks of theoretical abstraction and a deterministic cultural politics. Our following section, 'Pausing', recounts an ordinary organizational encounter as a means to reflect on the significance of everyday affects. In the subsequent section entitled 'Organizing' we move on to consider previous accounts of affect in organizational life, and explore how affects are subjected to, and generated within, current expressions of gendered organization. In the penultimate section named 'Becoming', we consider how the process of becoming-woman, as articulated by Deleuze and Guattari (1988) and extended by Braidotti (1994, 2003), may open an affective, corporeal and political intensity that resists and subverts the gendered organization. In 'Concluding', we assess the position we have arrived at, and how it may rejuvenate organizational thought and politics.

Methodologically, our paper is an assemblage where our heterogeneous bodies, subjectivities and habits come together across time and space to work with a range of philosophical and organizational writings. At moments we articulate various mundane experiences, and at other times we work through our experiences conceptually. We are mindful that each of us is not constituted by, or expresses, the same affects. Yet, the affective encounters that this paper represents stem from different bodies which have met and agreed upon some 'common notions', to use Spinoza's (1994: 138-141) term - that is, some concepts and modes of operation that the three of us can relate to. There is difference and variety within our harmonious relations, but, as Spinoza (1994: 221) would insist, our capacity to affect and be affected can only flourish through difference.

\section{Affecting}

The affective turn almost exclusively starts with the philosophy of Spinoza (see Massumi, 2002a; Hardt, 2007), usually en route through the work of Deleuze and his collaborations with Guattari (see e.g. Clough et al, 2007). Consistent with this tradition, Spinoza's (1994[1677]) philosophy, and Deleuze's engagement with Spinoza, is fundamental to the understanding of affect we develop here. In the Ethics Spinoza defined affect, or affectus, in terms of power and capacity as the body's desire and ability to affect and be affected by other bodies: "By affect I understand affections of the body by which the body's power of acting is increased or diminished" (1994: 154). For Deleuze (1992), who disregards Hegel's (1969[1817]) complaint that Spinoza neglected the power of the negative, this underlines the expressive and affirmative character of affects. Although Spinoza distinguished between positive and negative affects by using the terms 'joyful' and 'sad', he acknowledged their overlaps and inconsistencies, as well as their dynamic and imperfect nature. Sad affects may pass into joyful affects, and vice versa (e.g. 1994: 188). It is this which makes Deleuze (2007) note that for Spinoza "a power of being affected is really an intensity or threshold of 
intensity" (n.p.); it is the passage between sad and joyful affects, which affects us so much that we are overwhelmed, so little that we are under-stimulated, or so much that our capacity to affect others is enhanced.

In the introductory notes to his translation of Deleuze and Guattari's A Thousand Plateaus, Massumi (1988: xvi) echoes these sentiments, arguing that affect "is a prepersonal intensity corresponding to the passage from one experiential state of the body to another [...]." Hence, it is through changes in what we experience that we are affected. Conversely, the argument would be that experiential stability, whether caused by psychopharmaceuticals, lobotomy, withdrawal or monotonous work, desensitizes us and leaves us unaffected. The intensities of affects are therefore augmented through pressures, constraints and boundaries that increase or diminish what bodies can do, and through our acts and movements as locate between the margins of a present situation (Massumi, 2002b). Without sedimenting the difference between joyful and sad affects, this may happen negatively, for example when performance targets take time away from any activity un-related to work, or positively, for commuters who start cycling to work because of the rush-hour traffic congestion caused by cars.

While centrally influenced by Spinoza and Deleuze, Massumi elaborates a notion of affect that exceeds their work by engaging with contemporary psychology and neuroscience. Massumi argues that affects are asignifying and extra-linguistic intensities, involving nonintentional and unconscious forces that escape meaning and precede and exceed psychology's categories of affects and emotions (Massumi, 2002a). Thus, emotions are partial expressions of affect that we express outwardly and which we are conscious of. As a result, the focus on emotion excludes the affects which involve visceral perceptions and autonomic responses (Massumi, 2002a) and which emerge from an open-ended sociality of relations between humans (see also Clough, 2007). For instance, experimental studies in psychology illustrate how the affects of non-verbal visual imagery on film exceed those expressed by adding verbal explanations to the non-verbal original (see e.g. Massumi, 1995). Language, then, does not add to the non-verbal affective experience, but detracts from it.

Despite their contributions, Massumi and other affect theorists (e.g. Connolly, 2002) have been criticized for offering little beyond contemporary psychology and neuroscience, and when doing so, for ending up in vague and abstract speculation. As Leys (2010) points out, the anti-intentionalism pursued by affect theory is shared by mainstream psychologists of emotion (e.g. Tompkins, 1984; Ekman and Davidson, 1994) who limit the meaning of affect to unconscious and non-intentional brain-body behaviours. Moreover, Massumi (2002a) reduces affect to a virtual intensity, that is, a latent tendency, and an "incorporeality of the body" (p. 21) which is "inaccessible to the senses" (p. 133). Hence, "affect can only be grasped topologically, which is to say, unempirically" (Leys, 2010: 468n62; see also Massumi 2002a: 134), that is, only in terms of its general qualities but not in terms of its actual experiences. In our view, this reveals at least two problems with Massumi's programme for affect theory. Firstly, his exploitation of empirical studies to illustrate his theory of affect coupled with his rejection of the shear possibility of studying affects empirically is inconsistent. Secondly, his unequivocal emphasis on the virtual and incorporeal nature of affects short-circuits Deleuze's (1994) ontology by disconnecting virtual intensities from actual lives. Consequently, affect is reduced to a matter of undifferentiated, latent and disembodied tendencies that have little bearing on, or grounding in, the lived, let alone mundane, multiplicities of human experience.

We do not feel that these problems are quite resolved in parallel attempts by others to 
theorize and politicize affect, or in later attempts by Massumi (e.g. 2015) to do so. Clough, for instance, has sought to tune the affective more directly into political economy by interrogating how capital and biopolitical forms of control are entangled with the affective capacities of bodily matter. With reference to affective labour, Clough argues that capital seeks to capture and exploit the human capacity, potential and vitality of the organic body through "continuous modulation, variation and intensification of social cooperation" (Virtanen in Clough, 2005: 23). In the global affective economy, she suggests, the capitalization of affect further works through an augmentation and networking of bodily differences, as when urban children are refined through education while rural migrant workers are exploited as cheap labour. Ultimately, this makes bodies valuable or valueless, hateful, and deserving to die.

We might agree with Clough that this is not merely a matter of socialization, subjectification and interpellation, of attributing value and worthlessness according to differences of race, religion and nation, class, gender and ethnicity. Affective forces enable and exceed such sedimented categories, as when urban children as well as rural migrant workers come to fear the "threat [...] of failing to be a body of value" (Anagnost in Clough, 2005: 24). However, both here and in later writings, Clough largely adds the affective onto the cultural politics of racism, sexism and nationalism, and speaks of the affective in rather abstract terms (see e.g. Clough, 2008; Clough and Willse, 2011). This risks trivializing the ontology and politics of affect as well as the politics of culture and identity. It also becomes less clear what difference an exploration of the extra-linguistic, pre-cognitive and unconscious affective makes to the operation of racism, sexism and nationalism. This prevents us from examining in any concrete sense how affect is entangled in technologies of oppression and exploitation, how the indeterminacy and capture of affect is experienced, and how it may reconstitute and transgress the social, political and economic order of racism, nationalism, capitalism and globalism. At the same time, we do not sense that a resolution of these problems lies in theorizations of affect that go too far in the opposite direction. Ahmed's (2004) psychoanalytical notion of 'affective economies' is one such account, and which has been influential in showing how emotions of hate and fear become attached negatively to the bodies of certain racialized people, as when racist western groups differentiate themselves from non-western groups by conflating asylum seekers and terrorists alike into a fearful, inferior and dangerous other. Although this perspective establishes a cultural politics of identity that concretizes how affects circulate between bodies, it reduces affect to a surface matter of social emotions which ignores how the social expression, circulation and exploitation of emotions is informed, and overwhelmed, by a variety of lived experiences and visceral feelings.

In their own way, then, affect theory's tendency to avoid a detailed treatment of embodied and lived experience cloaks what is at stake in the questions that we are concerned with: How does the gendered organization oppress us by seeking to capture and exploit our affects? And how can affect transgress the gendered organization and its hierarchy which privileges men and masculinity over women and femininity? Attending to these questions, we must consider affect in ways that matter for people and our bodies. We must explore the lived and actual intensities of affective politics within and around organizations, without getting caught up in concepts that reduce affect to surface emotions and sedimented categories but appreciates how real people with real bodies might experience and challenge the gendered organization. We must acknowledge how affects bring people together by passing between us, without ignoring the nuanced and differential ways in which the gendered organization affects us, and is affected by us, across the corporeal and political registers of social and organizational life. 


\section{Pausing}

I (one of the authors) was asked to attend a formal work dinner with external 'stakeholders' of my Faculty. As I arrived at the upmarket hotel where the dinner was being held in one of their private dining rooms, I met two of my colleagues who had also been asked to attend. We walked along the corridor of this harbour side venue, noting the spectacular views of the water. It was then that I noticed that other members of my department were attending a rather large party. Given that I had only recently joined the institution, I spotted the Dean and decided to say 'hello' because I thought it was rather odd that we had not yet met or been introduced. When I spoke to him he was very warm and friendly, and he said rather embarrassingly: 'I wondered where you were'. I said I was at the hotel for a department dinner and did not know about this event. I found out later that the two events had been purposefully held at the same place so that the external guests at the dinner could go to the Dean's reception first. He said that, as a new member of staff, I should have had been invited to attend his annual drinks reception. He called his marketing director over and she informed me that the invitation list had been provided by my Head of Department. Clearly the Head has not passed it on.

I remember feeling cast out, excluded, but I was also very curious as to why the invitation hadn't been forwarded to me. I asked the Head of Department who was circulating around the room rather busily. I was rather preoccupied by the range of staff present, including an administrator prancing around in a gold coloured full length evening dress drinking champagne. The Head said: 'There will be other times' and abruptly ended the conversation. I recall thinking how quickly one can become disaffected by an organization. I thought about how, at key moments in a new job when events are created to ensure you are welcomed, individuals and their oversights so easily provoke negative emotions. I am not sure I would have enjoyed the drinks, but I had been overlooked and I suspected it had been done on purpose. When trying to seek information to know why I was further isolated. I left and entered the private dining room. I looked around and thought: 'why am I here?' I remember thinking I should have dressed more formally. I ate the prawn starter. The wine was delightful. Unprepared and without forewarning I was asked to address the group to talk about my research. I was out of place yet again. I needed to speak with commitment about my work and what I was bringing to my institution.

As I write this now, some years later, I still feel the deep sigh that emerged from my gut that evening. I remember the hard hit of a heavy, throbbing pulse. I remember too controlling my response and having to contain the visceral affects with which my body responded. What would the consequences be of giving in to these affects? Affective containment requires order, control, and organization of the body. Giving in to the visceral would be unprofessional, chaotic and, maybe, hysterical.

\section{Organizing}

Affective relations between bodies and the constructs we use to think about, order and evaluate bodies have received increasing attention in organization studies as a means of thinking through the principles and implications of affectivity in organizational life - from electricity companies (Lohmann and Steyaert, 2006) to NGOs (Kenny, 2012) and activist communities (Vachhani, 2013) (see also Kenny and Fotaki, 2014; Pullen and Rhodes, 2014; 
Thanem and Wallenberg, 2015). With reference to a Deleuzian conception of affect, Lohmann and Staeyert's (2006) research on deregulation in the Danish electricity industry suggests that employees' affective engagement for genuine change can reject dominant discourses of organizational change, contest the dominant majority, and unfold unforeseen possibilities against the powerful's effort to control the future. Drawing on Lacan's notion of the linguistic, extra-individual and social-political nature of the psyche, Kenny's (2012) study of an NGO suggests that affect informs recognition and identification as people in organizations desire to be recognized by powerful others. As the NGO was highly dependent on external funding, employee feelings of self-belief were strengthened by being recognized by a big government funder, even though people working there were initially sceptical of becoming part of a 'big government' agenda. For these NGO workers, the power of recognition made it feel so good to be recognized by the powerful other that they sought recognition by adjusting their expectations and practices to fit in. In a different vein, Vachhani's (2013) study of the 'craftivist' group Knit the City shows how political messages can be communicated through objects of craft-work. Through their very tactility and creativity, traditional craft practices and the objects they produce evoke memories of the past and bring out affective intensities that spur bad and good feelings of frustration and powerlessness, joy and happiness, which in turn stimulate political action.

While this literature does not coalesce around a central body of ideas, assumptions or conclusions, one feature that does unite it is the connections it makes between affect, politics and organizational change. In other words, these contributions relate affects to practical political matters of how authoritative power and oppression is experienced and how we may craft and express lived political responses to it. Having said that, in the same way that we saw with Massumi's and Clough's work earlier, these writings can be collectively criticized for rendering affect in a somewhat nebulous and disembodied manner. Physical, visceral and sensate bodies are largely absent, and affects are in danger of being akin to the more limited notion of feelings: Kenny's (2012) emphasis on the linguistic origin of the psyche's sociality risks ignoring the corporeality of affects by reducing affects to a matter of linguistic expression; the (imagined) bodies in Lohmann and Steyaert (2006), and Vachhani (2013), lack flesh and blood, live expression and visceral experience. As a result, this literature ends up examining the political potential of affect without explicitly considering the bodies who might enact it. In this paper our aim is to extend theories of affect generally and in relation to organizations, to move beyond the realm of conceptual knowledge and into the lived political realities that people inhabit, to explore the corporeal, social and political intensities of affect in relation to the concrete and everyday conditions in which we live and work. We propose that by introducing affect into the theory of the gendered organization we can advance a social and political critique of affection and its expressions, which challenges injustice and inequality in current forms of gendered organization.

As highlighted in early parts of the paper, gendered organizations continue to shape conditions of life and work in ways that reproduce asymmetric and unfair relations between women and men. Consequently, gendered organizations provide an important site for exploring, exemplifying and extending the affective in concrete and corporeal terms. Acker's notion of the gendered organization emphasizes how male-stream institutions reinforce gender discrimination in organizations through an unequal and unfair distribution of advantages and disadvantages (Acker, 2009). Based on ideal images of men's and women's bodies and bodily difference, gendered organizations take the male body for granted (Sinclair, 2005), devalue women's bodies, and associate the male body with action and rationality but the female body with emotion and passivity. These assumptions feed into 
predominant notions of a disembodied and "abstract worker doing [an] abstract job" (Acker, 1990: 149). In this way stereotypes between men and women in organizations are perpetuated in practice where men are deemed capable of controlling their emotions while women are associated with having uncontrollable and messy emotions (see also Knights and Kerfoot, 2004).

In spite of claims from the political right (Devillard et al, 2013) and left (Smith, 2008) that gender has ceased to be a central category of politics, current statistics tell a different story. Almost half a century since equal pay legislation was introduced in western countries, labour markets are still characterized by broad gendered pay gaps, whose closure is far from imminent (O'Reilly et al, 2015). In Sweden, commonly regarded as a progressive nation, women's income make up 87 percent of men's income, and women occupy 19 percent of all top management positions in publicly traded companies (Dagens Nyheter, 2015). In a more startling statistic, amongst the 1,500 corporations listed in Standard and Poor's stock index, there are four times more chief executives named John, Robert, William or James, than there are women chief executives (Wolfers, 2015). However, the gendered organization has come to operate in more subtle and contradictory ways than Acker's (1990) writings imply, as discriminatory practices co-exist with anti-discriminatory claims in both business and legislative discourse. In countries such as Sweden, where labour legislation forbids recruitment and promotion decisions to be influenced by parental concerns, women (but not men) are frequently confronted with and disadvantaged by such questions. Even amongst the growing number of companies that pride themselves on their alleged capacity to achieve commercial advantage by maximizing diversity, young women tend to be judged on experience while young men are more likely to be judged on potential (e.g. Dagens Nyheter, 2015). Moreover, assumed gender neutrality and the denial of gender discrimination is manifest among many token women in top management, and among many of our young women business students who aspire to reach such positions.

The practical and political question that arises out of these observations is not altogether different from the question that emerges out of Acker's (1990) analysis: namely, how can we "build less oppressively gendered organizations" (Britton, 2000: 431)? Even though women are increasingly present in management positions, women's bodies and women's unique bodily experiences remain largely absent, subservient to the masculine organization and palpable only in sex work (Wonders and Michalowski, 2001), retail work (Pettinger, 2005) and other forms of work where the body itself is commoditized, exploited and traded. The female body, replete with its capacities for reproduction, menstruation, menopause, lactation and fluidity (Grosz, 1994) is hidden from view in organizations, sequestered and rendered abject in the event that it might interrupt the uprightness of masculinity. In other words, woman's carnality is 'gutted out' and 'effaced' from organizations, and women are scarred and made abject in the process (Fournier, 2002).

To restore the "absent female body" (Acker, 1990: 154), the fundamentally gendered structures of work and organization would therefore have to be challenged, and change, at their core. But while previous accounts have tended to be overwhelmed by the oppressive structures of the gendered organization and underestimated the subtle and contradictory ways in which it increasingly operates, our attempt at a radical politics in organizations requires us to further unfold bodies as sites of affect. As presaged earlier, we therefore turn to explore how the affective trajectory of becoming-woman (Deleuze and Guattari, 1988) may challenge the oppressive structures of gendered organization. Despite the development of process theory in organization studies and its emphasis on becoming, exponents of this theory have 
employed it in relatively apolitical and disembodied ways (e.g. Clegg, Kornberger and Rhodes, 2005; Linstead and Thanem, 2007). However, becoming-woman urges us to radically reconsider this position by building on the realization that becoming does not merely involve processes of open-ended change, but processes that are enacted and experienced through inter-corporeal encounters (Thanem, 2006), which affect our capacity to act upon and be acted upon by others.

\section{Becoming}

According to Deleuze and Guattari (1988), becoming-woman is a 'minoritarian politics' that holds out hope that individual potentiality can be realized as an effective subversion of exploitative and oppressive regimes of power, including, we add, those of the gendered organization. Becoming-woman does not specifically or exclusively refer to biological females as "defined by her form, endowed with organs and functions and assigned a subject" (Deleuze and Guattari, 1988: 303). Neither is it about imitating an image of what it means to 'be' a woman. The ontological focus is on becoming rather than being. This becoming is an open-ended process and is not in pursuit of the fixed or predefined positions that are privileged in dualist ontologies. Becoming transpires along an indeterminate trajectory, towards an unknown end, rather than specifying a destination that holds within it any controlling or limiting notions of subjectivity or bodily capacity. In the case of the gendered organization which prescribes gender norms that influence expected behaviours of men and women, becoming undoes the conceptual opposition of the masculine/feminine binary and undoes the (re)production of essentialist divisions between man and woman. Becomingwoman is a liberating process that engenders possibility to move away from established norms that constrain embodied habits and experiences. Possibility manifests in freedom from the restrictions of subjectivity.

Becoming-woman is not just a philosophical concept, but a practical political matter that can be "found in antislavery movements, feminism, gay/lesbian rights movements, [and] the introduction of secularism" (Connolly, 1999: 59). Such movements witness how oppression and exploitation are experienced by bodies, and how they are exercised on us as individuals because we have certain 'types' of bodies. However, as we indicated earlier, negative affective experiences are not merely negative, but can instigate processes of becomingwoman as they trigger people to craft new habits and capacities by experimenting with what bodies can do, against and beyond exploitative and oppressive regimes of power and subjectification. Rather than moving towards a fixed or essentialized notion of what a woman is or should be, becoming-woman is a movement that undermines the "man-standard" (Deleuze and Guattari, 1988: 321), which in organizational terms subsume men's bodies into the ideal "image of the worker" (Acker, 1990: 139). Becoming-woman is thus a political and affirmative response to mundane forms of oppression, to the masculine body-norms that render women as 'other', and to the masculine gendering of organizations as competitive, hard, rationalist and penetrating like the bodies that men are told they should aspire to having. Braidotti accentuates the significance of becoming-woman. Given that "woman is the privileged figure of otherness in Western discourse", becoming-woman is a primary form of becoming and "a general process of transformation" (Braidotti, 1994: 114).

While we attest to the political possibilities of becoming-woman, riding this trajectory to develop an affective politics in gendered organizations also requires us to question its deployment of the word ‘woman'. As Grosz (1994) acknowledges, Jardine (1984, 1985) and 
Irigaray (1985) have criticized becoming-woman for being "a male appropriation of women's politics" (p. 163) which deactivates the specificities of women's sexed bodies by distracting attention from the presences of men's interests and neglecting how real women suffer from "exclusion and denigration" (p. 163). Moreover, Deleuze and Guattari's intention to transgress gender dualisms would lose 'woman' as an ontological category. On account of this becoming-woman fails to recognize that woman is a pivotal and powerful subject position that has been deployed in feminist theory and political movements (Braidotti, 1994; Grosz, 1994). Becoming-woman therefore risks neutralizing sexual differences so as to "damage the process of reclaiming a political subjectivity for women" (Braidotti, 1994: 122). While not denying these criticisms, we concur with Grosz and Braidotti that they serve as an impetus to reconsider the potential of becoming-woman rather than to abandon it.

More recently, Braidotti (2003) has pointed out that Deleuze and Guattari prioritize 'woman' and sexual difference because it is the primary axis of differentiation. This is particularly the case in organizations, we may add. Further, Braidotti (2003; see also 2006) argues that we can retain the notion of becoming-woman by relating it to feminist politics and the struggle to redefine embodied subjectivity as it plays out in localities of practice. As this body is "an interface of [...] material and symbolic forces", it is both inscribed by multiple codes such as sex, race, and class, yet capable of mobilizing "heterogeneous, discontinuous and unconscious" energies (p. 44) that circulate and proliferate across and beyond these codes and their efforts to capture, control, commodify and exploit the body. Engulfed in a feminist politics, becoming-woman thereby allows subjectivity to flourish outside of its dominant masculine ordering without dismissing the value of woman as a subject-position or gendered body, and without reducing it to simple bodily dualism. Rather, becoming-woman is an affective force that encourages us to experiment with gender difference, re-embody masculinities and femininities, and recompose relations between women and men. Consequently, becoming-woman promises new possibilities by rethinking ontology as an affective process and rearticulating politics in subversive yet affirmative terms. With becoming-woman, empowerment enhances what embodied subjects can do by involving us in joyous encounters that increase our capacities to affect and be affected, across, against and beyond any putative hierarchical division of mind over body, man over woman.

Engaging with the affective trajectory of becoming-woman becomes particularly important at a time when sexual difference is a more multi-layered, ambiguous and contested term than ever (see also Braidotti, 2002: 260) and when the gendered organization is working itself into the lives of men and women in subtle and confusing ways. Besides challenging the gendered organization's hierarchical modes of oppression, becoming-woman prompts us to do so through the real and moving body of a person. Given our concern to reconnect mundane experiential realities with affective politics, there is an inevitable question of what becomingwoman might 'look like' in practice: How do we re-embody masculinities and femininities and recompose relations between women and men? It is difficult to outline a straightforward and solid programme of how becoming-woman can be played out in organizations.

Becoming-woman cannot be achieved through a series of simple steps and procedures. Even though it can (and should) be illustrated with examples of concrete practices, their capacity to challenge the gendered organization will always be imminent, situationally negotiated and contingent. This makes it no less practical, and a starting point is to explore how women and men experience and respond affectively to the oppressive structures of the gendered organization as they manifest in daily practices. 
It is crucial to realize that the response to the gendered organization does not have to involve only apathy and cynicism, compliance, resignation or incorporation. Just as we saw in the vignette that introduced this paper, affective responses can also come in the form of embarrassment and shame, frustration and anger, which is felt and expressed through our bodies. However, as we discussed earlier, such affects are not simply negative, but can trigger radical (but not predetermined) political action. Instead of putting me back in 'my place', the embarrassment and unease I (one of the authors) felt during the encounter with my male boss in the elevator sparked a sense of frustration and anger that is moving me to challenge male-stream attempts at micro-dominating myself and my colleagues. Other experiences may stimulate us to break dress codes, speak outside of gendered scripts, and step out of stereotypical or 'appropriately' gendered habits. They may trigger us to break the inane yet normalized habit of involuntarily laughing at sexist jokes and instead share counterjokes and experiences. They may move us to refuse to 'manage like a man' and instead embrace role models that deny, surpass or undermine the assumption of masculinity. They may motivate us to stop denying gender discrimination and force us to care about people around us, in ways that exceed the masculine ethos of individualistic competitiveness and performance maximization that often informs the deployment of diversity management and the promotion of token women executives. To be sure, these kinds of mundane everyday responses do not enable us to change the world in one fell swoop; indeed, such heroic fantasies would already be playing into masculine desires. Instead, small things matter, and there are no universal solutions to destabilize the false and oppressive male/female dichotomy that underpins the gendered organization. Rather, the Spinozian legacy of affect theory and affective politics means that we need to open ourselves up to new encounters with others, which creatively move our bodies towards more joyful possibilities, of living, working and organizing.

As we have already established, affects involve us in a sociality that springs out of embodied interaction. Without loss of bodily differences, this sociality includes "all the attractions and repulsions, sympathies and antipathies, alterations, amalgamations penetrations, and expansions that affect bodies of all kinds in their relation to one another" (Deleuze and Guattari, 1988: 99). This is precisely the sociality that constitutes organizations. And as the affective trajectory of becoming-woman works against ingrained tendencies towards individualism, it makes clear that the possibilities and potential of any person can only be realized through embodied interaction with others and the political possibilities this opens up. By scrambling transactions between predefined selves, our affective relations with others in organizations change the meaning of what it means to be a self, right here, right now. In organizations, an affective politics of becoming-woman re-embodies us in our everyday milieu, and it does so with sexed bodies that carry with them life's events. Our carnal bodies are full of imperfections and vulnerabilities. But even though we are constantly targeted by organizational attempts to regulate us, improve us, co-opt us and exploit us, we are capable of leaking our private fluids into public spaces, and generate floods that run counter to the main streams of the gendered organization. These leakages tie us together in a joint struggle against gendered oppression in everyday life, work and organizations.

Admittedly, organizations might not be obvious sites for becoming, but given how much time we spend in them during our working lives, to ignore the political potential of embodied everyday affects underestimates the extent to which we can mount resistance against their oppressive structures and cultures. Change is only possible if we rethink the conditions by which we live our lives in organizations. The shame and hurt shared in the prologue can be debilitating; but it can also give rise to generous, joyous acts where individuals multiply each 
other's power through interaction. The fact that there are organizations (including universities) where power continues to be embedded in and enacted through the masculine order makes them an important site for the affective politics of becoming to be crafted. As the masculine order of gendered organizations re-inscribes itself over and against their apparent pledges for gender equality and diversity, it limits who we can become, and casts us all, men and women, in a restrictive and limited conception of the masculine (see Wajcman, 1998; Knights, 2015). But even though organizations tend to produce sadness rather than joy, organizational regimes are never total, and, as Spinoza indicated, human interaction always harbours the possibility for sad affects can be transformed into joyful affects which exceed and subvert the gendered organization.

\section{Concluding}

At the outset of this paper we pointed out that there is an imbalance in previous writings in affect theory, where either politics is privileged over embodiment, or theoretical exposition is favoured over corporeal exploration. We also noted that affect has been conceived of as abstract and anti-empirical, or political yet disembodied. Through the practice of becomingwoman in organizations lies the possibility of an affective trajectory that, both corporeal and political, mitigates against these tendencies by contesting the everyday oppressions of the gendered organization. Oppression, whether exercised through sexual harassment, sexist jokes, masculine normativity, gendered pay gaps, or the undermining of individuals, generates experiences of abuse, injustice and unfairness that are felt through our bodies. Whilst these forms of oppression are sad affects that diminish our power to act in the moment, the affective politics we have proposed in this paper asks us to question how we might respond affirmatively to them, by seeking joyful encounters that enhance what we can do.

Deleuze and Guattari (1988) acknowledge the masculine order that dominates western society and develops becoming-woman as the primary trajectory of becoming. As the masculine order infiltrates organizations in ever more intricate ways, becoming-woman has offered us an affective opening to interrogate the gendered organization and to articulate ways of combating the lived, often sad affects of gendered exclusion and discrimination that are passed onto bodies in organizations every day. Despite a surge in organizations' officially communicated intentions to recruit and promote a more diverse workforce (go to hm.com, ikea.com, monsanto.com or just about any corporate website for examples), the majority of organizations remain gendered hierarchies. On the still rare occasions that women do enter the echelons of top management, they typically negotiate and fit in with the masculine culture by 'managing like a man' (Wajcman, 1998). Even (or especially) when this is combined with stereotypically feminine images and dress practices, token women executives submit to masculinized traits of competitiveness, toughness and rationalism to succeed and stay on top. Not doing so bears the risk of becoming further 'othered' by the homosocial and statuspreserving cultures that characterize these arenas.

Exploring affect in organizations has made us realize that theorizing, thinking and writing are not ends in themselves, but pathways to live and work with others in a manner that refuses the assumed necessity of austere sadness. This does not mean that thinking is not important; quite the contrary. Thinking, as manifest in theory and philosophy, is a force through which we can imagine human capability and interaction, such that a political pursuit of that imagining might ensue. Affect theory, we thus conclude, has value in its theoretical richness 
so long as it supports and engenders political action at the level of embodied social interaction. Its purpose is to generate a politics that enables people to break out of the sad regimes that oppress us. This politics is not to be confused with naïve idealism or utopianism. It does not wait for a messianic day where bodies only ever feel joy, and where corporeal encounters with others only ever result in the increased power of bodies. If there is an idealism in place, it is one that never forgets joy as a trajectory worthy of continual pursuit.

How, then, might our writing, at times arcane, help advance an affective politics that can combat the gendered organization and its oppressions as they manifest in everyday life? To begin with, we maintain that bringing together divergent strands of affect theory has raised the importance of infusing an affective politics of organization with a politics of becoming. This arms the everyday with radical potential by asking the seemingly mundane question of what bodies can do. But 'Voicing the mundane is a means to puncture some of the posturing that haunts academic work' (Gregg, 2004: 364). This actually makes us more sensitive to the political implications of theory - to the sad affects that the gendered organization generate in us and between us, and to the joyful affective encounters that might challenge it. So, as much as we have engaged with theory, this paper has also spurred us to collect and share some of the affects that have surfaced whilst we study and work in organizations ourselves. This "affective tone" reminds us of our own place "in the culture under investigation" (Morris cited in Gregg, 2004: 364). Despite the pretence of our academic prose we want not to forget that the linguistic tools we use are always secondary to the real possibilities of how an affective politics can destabilize and reform the gendered organization. The problem of "how to account for practical knowledge" (Probyn, 2004: 335) is ever present and we have no neutral language to do it. As our personal experiences show, representing the everyday enables this practical knowledge to become political action. Corporeal affect is "the action by which something or someone continues to become other" (Deleuze and Guattari, 1994: 177), on a plane of sensation. Affects are "visceral points", "hunches" which move us (HickeyMoody, 2013: 81) to act. As the vignettes in this paper reveal, the visceral lives on well beyond the events in which we first experience them. The body remembers and there are times when people and organizational experiences take you back to those affects of the drinks party and elevator. And of course, if we are containing our affects, then we do so in the very containment of other's affects. The trajectory of affective politics is one that embraces those affects and re-routes them to a resistance to the gendered organization.

This paper has accounted for our embodied knowledge within our own limitations and the constraints that language poses on us, recasting the affective sociality of our bodies in such a way that the need for and possibility of an affirmative politics relevant to everyday life becomes apparent. Embodied affects are practical and political, they are the means through which we remake ourselves. As Deleuze and Guattari suggest "the person who experiences the force produced by an affect can retain this force and be changed as a result of their experience" (Hickey-Moodey, 2013: 86). As gendered organizations burden us with the weight of oppression and exploitation, this makes us ask how we can actively resist the negative affects they engender, but also, more broadly, what future is possible? If we hope to achieve anything with this endeavour it is not to have the last word, but to open discussion and deliberation about the possibilities for transformation. Following Braidotti (2010), transformation involves the dynamic view of all affects where the central political question is "how to resist the present", particularly "the nastiness, violence and vulgarity of the times" in ways that are "worthy of our times" (p. 42). Connecting this affirmative politics to a contestation of the gendered organization, we conclude by suggesting three emergent problematics. 
First, if we accept that the affective components of subjectivity are corporeal effects of power, our actions can only influence organizations by "engendering empowering modes of becoming" (Braidotti, 2010: 45) through bottom-up intrusion. In addressing the possibilities of political action in gendered organizations, we must therefore continually explore alternatives without just dreaming of a forever deferred and idealized future. Such alternatives might, for example, involve efforts to transform habits and values in organizations, abandon dualistic thinking, and craft sustainable futures that refuse malestream norms of individualistic competitiveness and rationalism. Activating these forces can only occur through corporeal encounters with others, which prompt us to think differently about ourselves and relate differently to others.

Second, an affirmative politics requires us to reconsider otherness. Gendered organizations are built on the exclusion of those constructed as other and based on restricted understandings of gender. If we are serious about challenging gendered hierarchies and the structural otherness embedded within them, we have to start looking at how otherness can be a site of affirmation rather than negation. Through becoming, otherness emerges as a positive force that activates marginalized groups in organizations whilst destabilizing the dominance of gendered power relations and structures.

Third, an affirmative politics triggers us to reject simple dichotomies between sadness and joy, and transform negative affects into positive affects. Negative affects surround gendered organizations. They drag us down, rob us of energy, and sap the joy out of our lives. We have learned to endure the gendered organization and its effects on our bodies, and "sustain[-] the pain without being annihilated by it" (Braidotti, 2010: 50). But this endurance is what makes a different future possible; it is our endurance of sad negative affects that moves us to recast the body's capabilities along an affective trajectory of becoming-woman, which subverts, exceeds and combats institutional discrimination and oppression. Hence, an affirmative politics entails mustering this endurance for the purpose of transformation rather than mere survival.

Following these lines of inquiry and enacting this affective politics offers a process through which the gendered organization is usurped. While the gendered organization is currently rearticulating and reinventing itself through tokenism and ostensibly gender-blind competitiveness, it can only sustain itself as long as those of us who work in this regime ignore or misinterpret the sad affects that it still produces, and close ourselves off from joyful affects that interfere with it. Indeed, exaggerating the power of the gendered organization may be just as devastating for the pursuit of joyful encounters, as underestimating it. The possibilities of an affective politics ushered on the waves of becoming-woman gives us some hope that gendered organizations can be engaged in practically and theoretically, through affirmative questioning of subjectivity, otherness and dualistic ways of thinking and being. The transformational force of affects mobilizes an everyday radicality, and recasts the emphasis so that we can start un-gendering organizations rather than just bemoaning the overwhelming and oppressive gender structures that sustain them.

\section{References}

Acker, J. (1990) Hierarchies, jobs, bodies: A theory of gendered organizations. Gender and Society 4(2): 139-158. 
Acker, J. (2006) Inequality regimes gender, class, and race in organizations. Gender and Society 20(4): 441-464.

Acker, J. (2009) From glass ceiling to inequality regimes. Sociologie du travail 51(2): 199217.

Acker, J. (2011) Women, work, and politics: The political economy of gender inequality. Contemporary Sociology: A Journal of Reviews 40(5): 596-597.

Ahmed, S. (2004) Affective economies. Social Text 22(2): 117-139.

Braidotti, R. (1994) Nomadic Subjects: Embodiment and Sexual Difference in Contemporary Feminist Theory. New York: Columbia University Press.

Braidotti, R. (2002) Metamorphoses: Towards a Materialist Theory of Becoming. Cambridge: Polity Press.

Braidotti, R. (2003) Becoming woman: Or sexual difference revisited. Theory, Culture and Society 20(3): 43-64.

Braidotti, R. (2006) Transpositions: On Nomadic Ethics. Cambridge: Polity Press.

Braidotti, R. (2010). On putting the active back into activism. New Formations, 68(1), 42-57.

Britton, D.M. (2000) The epistemology of the gendered organization. Gender and Society 14(3): 418-434.

Britton, D.M. and Logan, L. (2008) Gendered organizations: Progress and prospects. Sociology Compass 2(1): 107-121.

Clegg, S. R., Kornberger, M. and Rhodes, C. (2005) Learning/becoming/organizing. Organization 12(2): 147-167.

Clough, P.T. (2005) Political economy and the biomediated body. Paper presented at University of Leicester. Accessed 5 February 2015. http://www2.leicester.ac.uk/departments/management/documents/research/researchunits/cppe/seminar-pdfs/2005/clough.pdf

Clough, P.T. (2007) 'Introduction', in P.T. Clough and J. Halley (eds) The Affective Turn: Theorizing the Social, pp. 1-33. Durham, NC: Duke University Press.

Clough, P.T. (2008) The affective turn: Political economy, biomedia and bodies. Theory, Culture \& Society 25(1): 1-22.

Clough, P.T., Goldberg, G., Schiff, R., Weeks, A. and Wills, A. (2007) Notes towards a theory of affect-itself. ephemera 7(1): 60-77.

Clough, P.T. and Willse, C. (2011) Human security/national security: gender branding and population racism. In P.T Clough and C. Willse (eds) Beyond Biopolitics: Essays on the Governance of Life and Death, pp. 46-64. Durham, NC: Duke University Press.

Connolly, W.E. (1999) Why I Am Not a Secularist. Minneapolis: University of Minnesota Press.

Connolly, W.E. (2002) Neuropolitics: Thinking, Culture, Speed. Minneapolis: University of Minnesota Press.

Deleuze, G. (1992) Expressionism in Philosophy: Spinoza (trans. M. Joughin). New York: Zone.

Deleuze, G. (1994) Difference and Repetition (trans. P. Patton). London: Athlone.

Deleuze, G. (2007) On Spinoza, lecture at Université de Vincennes à Saint-Denis (trans. 'afterhailstorm'). Accessed 20 February 2015. <http://deleuzelectures.blogspot.se/2007/02/on-spinoza.html>

Deleuze, G. and Guattari, F. (1984) Anti-Oedipus: Capitalism and Schizophrenia Volume 1 (trans. R. Hurley, M. Seem and H.R. Lane). London: Athlone.

Deleuze, G. and Guattari, F. (1988) A Thousand Plateaus: Capitalism and Schizophrenia Volume 2 (trans. B. Massumi). London: Athlone.

Dellinger, K. (2002) Wearing gender and sexuality "on your sleeve": Dress norms and the importance of occupational and organizational culture at work. Gender Issues 20(1): 3-25. 
Devillard, S., Sancier, S., Werner, C., Maller, I. and Kossoff, C. (2013) Women Matter: Gender Diversity in Top Management: Moving Corporate Culture, Moving Boundaries. McKinsey Report, Paris, November.

Ekman, P. and Davidson, R.J. (eds) (1994) The Nature of Emotions: Fundamental Questions. New York: Oxford University Press.

Ely, R.J., Stone, P. and Ammerman, C. (2014) Rethink what you "know" about highachieving women. Harvard Business Review 92(12): 100-109.

Dagens Nyheter (2015) Jämställdhet: Drygt 85 år kvar till lika lön. 8 March, pp. 32-33.

Fleming, P. and Sturdy, A. (2009) "Just be yourself!": Towards neo-normative control in organisations? Employee Relations 31(6): 569-83.

Fletcher, J. K. (1999) Disappearing Acts: Gender, Power, and Relational Practice at Work. Cambridge, MA: MIT Press.

Fournier, V. (2002) Fleshing out gender: Crafting gender identity on women's bodies. Body and Society 8(2): 55-77.

Gatrell, C.J. (2013) Maternal body work: How women managers and professionals negotiate pregnancy and new motherhood at work. Human Relations 66(5): 621-644.

Gherardi, S. (1995) Gender, symbolism and organizational cultures. London: Sage.

Gregg, M. (2004) A mundane voice. Cultural Studies, 18(2-3), 363-383.

Gregg, M. and Seigworth, G.J. (eds) (2010) The Affect Theory Reader. Durham, NC: Duke University Press.

Grosz, E. (1994) Volatile Bodies: Toward a Corporeal Feminism. Bloomington, IN: Indiana University Press.

Hardt, M. (2007) What affects are good for. In P.T. Clough with J. Halley (eds) The Affective Turn: Theorizing the Social, pp. ix-xii, Durham, NC: Duke University Press.

Hegel, G.W.F. (1969[1817]) Science of Logic (trans. A.V. Miller). London: Allen Unwin.

Hickey-Moody, A. (2013) Affect as method: Feelings, aesthetics and affective pedagogy. In Coleman, R. and Ringrose, J. (eds) Deleuze and Research Methodologies. Edinburgh: Edinburgh University Press.

Irigaray, L. (1985) This Sex Which Is Not One (trans. C. Porter with C. Burke). Ithaca, NY: Cornell University Press.

Jardine, A. (1984) Woman in limbo: Deleuze and his (br)others. Sub-stance 44/45: 46-60.

Jardine, A. (1985) Gynesis: Configurations of Woman and Modernity. Ithaca, NY: Cornell University Press.

Kenny, K. (2012) "Someone big and important": Identification and affect in an international development organization. Organization Studies 33(9): 1175-1193.

Kenny, K. and Fotaki, M. (eds) (2014) The Psychosocial and Organization Studies: Affect at Work. Houndmills: Palgrave Macmillan.

Knights, D. (2015) Binaries need to shatter for bodies to matter: Do disembodied masculinities undermine organizational ethics? Organization 22(2): 200-216.

Knights, D. and Kerfoot, D. (2004) Between representations and subjectivity: Gender binaries and the politics of organizational transformation. Gender, Work and Organization 11(4): 430-454.

Lewis, P. (2014) Postfeminism, femininities and organization studies: Exploring a new agenda. Organization Studies 35(12): 1845-1866.

Leys, R. (2011) The turn to affect: A critique. Critical Inquiry 37(3): 434-472.

Linstead, S. and Pullen, A. (2006) Gender as multiplicity: Desire, displacement, difference and dispersion. Human Relations 59(9): 1287-1310.

Linstead, S. and Thanem, T. (2007) Multiplicity, virtuality and organization: The contribution of Gilles Deleuze. Organization Studies 28(10): 1483-1501.

Lohmann, P. and Steyaert, C. (2006) In the mean time: Vitalism, affects and metamorphosis 
in organisational change. In M. Fuglsang and B.M. Sørensen (eds) Deleuze and the Social, pp. 77-95. Edinburgh: Edinburgh University Press.

Massumi, B. (1988) Notes on the translation and acknowledgements. In G. Deleuze and F. Guattari, A Thousand Plateaus: Capitalism and Schizophrenia Volume 2 (trans. B. Massumi), pp. xvi-xix. London: Athlone.

Massumi, B. (1995) The autonomy of affect. Cultural Critique 31: 83-109.

Massumi, B. (2002a) Parables for the Virtual: Movement, Affect, Sensation. Durham, NC: Duke University Press.

Massumi, B. (2002b) Navigating movements. In M. Zournazi (ed.) Hope: New Philosophies For Change, pp. 210-242. Annandale, New South Wales: Pluto Press.

Massumi, B. (2015) The Power at the End of the Economy. Durham, NC: Duke University Press.

Misra, J. and Murray-Close, M. (2014) The gender wage gap in the United States and cross nationally. Sociology Compass 8(11): 1281-1295.

Munro, I. (2004) Information Warfare in Business: Strategies of Control and Resistance in the Network Society. London: Routledge.

Murray, P.A. and Syed, J. (2010) Gendered observations and experiences in executive women's work. Human Resource Management Journal 20(3): 277-293.

O'Reilly, J., Smith, M., Deakin, S. and Burchell, B. (2015) Equal pay as a moving target: International perspectives on forty-years of addressing the gender pay gap. Cambridge Journal of Economics 39(2): 299-317.

Özbilgin, M. and Tatli, A. (2011) Mapping out the field of equality and diversity: Rise of individualism and voluntarism. Human Relations 64(9): 1229-1253.

Pettinger, L. (2005) Gendered work meets gendered goods: Selling and service in clothing retail. Gender, Work and Organization 12(5): 460-478.

Probyn, E. (2004) Everyday shame. Cultural Studies 18(2-3): 328-349.

Pullen, A. and Rhodes, C. (2014) Corporeal ethics and the politics of resistance in organizations. Organization 21(6): 782-796.

Rogers, J.K. and Henson, K.D. (1997) "HEY, WHY DON'T YOU WEAR A SHORTER SKIRT?" Structural vulnerability and the organization of sexual harassment in temporary clerical employment. Gender \& Society 11(2): 215-237.

Seyfert, R. (2012) Beyond personal feelings and collective emotions: Toward a theory of social affect. Theory, Culture and Society 29(6): 27-46.

Shouse, E. (2005) Feeling, emotion, affect. M/C Journal 8(6). np

Sinclair, A. (2005) Body and management pedagogy. Gender, Work \& Organization 12(1): 89-104.

Smith, S. (2008) The politics of identity. International Socialist Review 57: n.p.

Spinoza, B. de (1677[1994]) The Ethics and Other Works (trans. E. Curley). Princeton, NJ: Princeton University Press.

Stainback, K., Kleiner, S. and Skaggs, S. (2015) Women in power undoing or redoing the gendered organization? Gender \& Society, 0891243215602906.

Thanem, T. (2004) The body without organs: Nonorganizational desire in organizational life. Culture and Organization 10(3): 203-217.

Thanem, T. (2006) Living on the edge: Towards a monstrous organization theory. Organization 13(2): 163-193.

Thanem, T. and Wallenberg, L. (2015) What can bodies do? Reading Spinoza for an affective ethics of organizational life. Organization 21(2): 235-250.

Time (2014) 'Company-paid egg freezing will be the great equalizer', 15 Oct. Accessed 15 Sep 2015. <http://time.com/3509930/company-paid-egg-freezing-will-be-the-greatequalizer/> 
Tomkins, S.S. (1984) Affect theory. In K.S. Scherer and P. Ekman (eds) Approaches to Emotion, pp. 163-195. Hillsdale, NJ: Psychology Press.

Townsley, N.C. (2003) Review article: Looking back, looking forward. Mapping the gendered theories, voices, and politics of organization. Organization, 10(3), 617.

Tsoukas, H. and Chia, R. (2002) On organizational becoming: Rethinking organizational change. Organization Science 13(5): 567-582.

Vachhani, S.J. (2013) (Re)creating objects from the past: Affect, tactility and everyday creativity. Management and Organizational History 8(1): 91-104.

Wajcman, J. (1998) Managing Like a Man: Women and Men in Corporate Management. John Wiley and Sons.

Wittenberg Cox, A. (2014) Seven Steps to Leading a Gender-Balanced Business. Boston: HBR.

Wolfers, J. (2015) Fewer women run big companies than men named John. New York Times, 2 March 2015. Accessed 9 March 2015.

<http://www.nytimes.com/2015/03/03/upshot/fewer-women-run-big-companies-thanmen-named-john.html?_r=0\&abt=0002\&abg=0>

Wonders, N.A. and Michalowski, R. (2001) Bodies, borders, and sex tourism in a globalized world: A tale of two cities - Amsterdam and Havana. Social Problems 48(4): 545-571. 